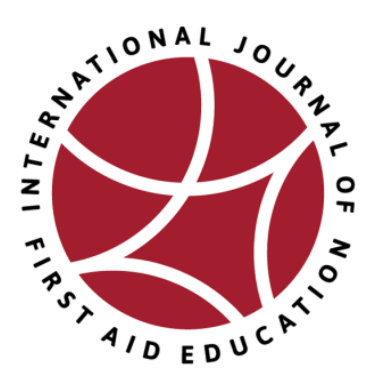

\title{
Response: Do we believe in fairy tales?
}

Dear Editor,

My first experience with First Aid Education felt like entering a fairy tale: Once upon a time in a land called 'First Aid' there was a great magician (First Aid instructor) who knew many technical tricks to deliver first aid skills. He would allow me to become his student, but never would I be able to reach his level of knowledge and skills. However, he was willing to open a tip of the curtain, so that I could have a short look in the magical world of First Aid.

Being a magician, there was no need for the instructor to show me any evidence or expert opinions, except his own. I believed every word he told me and studied hard to master the first aid skills and tricks he taught me. Later I realized that even magicians and illusionists make use of scientific evidence, mainly of neuro science: How to confuse and deceive people are skills that make use of knowledge of how the brain, sense organs and memory work (University of Leicester, 2013). Exactly the same domain (neuro science) is of great importance to First Aid Education. Not to confuse or deceive the students, but to help them to build the right propositions so that they can remember well, and to help them to store the skill knowledge in their memory in such a way that they can retrieve this information fast, if necessary. (De Vries, W., 2010)

Your call for a revolution (Pellegrino et al., 2017) implies a need to get rid of the 'magicians' and focus on knowledge construction, helping the student to strengthen his self-efficacy (Bandura, A., 1995). Some first aid skills ask for a special technique, most are just based on common sense. Instead of distracting students from their internal drive to help, we should help them in improving internal motivation to care. 'Caring is a natural human response' (Pellegrino et al., 2017).

And, I agree that we do need more evidence based First Aid Education. But do we need others to revise 'Educational Efficiency' and 'Local Implementation' factors into simple, common and consistent definitions, or might it be better to use new evidence, opinions and criteria to find common opinions about these factors? I am convinced that the IJFAE will help to operationalize definitions and that the published reports can improve self-efficacy of the first aid provider and quality control of first aid skills. 
The white paper asks for a revolution instead of evolution (Pellegrino et al., 2017). And I must agree that there is no time, nor reason to let the evolution decide how we deliver First Aid, how we learn First Aid or how we teach First Aid. Learning First Aid will be informal and formal. We will probably still need instructors to demonstrate First Aid skills and give us feedback. But our environment, our neighbours, our friends, our family, will teach us as well. The actual situation might influence the priority in learning. When one encounters a terrorist attack, one will have a higher motivation to learn how to control bleeding than learning how to act when a person is choking. On the other hand, once a person has learned to cool burning wounds, he will remember 'for ever'. Retention is high, retrieval is fast. But for CPR, one needs regular refreshment for optimal skill acquisition. But with what interval and how many minutes of training? (Greif et al. 2015).

I hope that a larger number of people decide to become revolutionists, joining us to spread First Aid in such a way that people will have more self-efficacy when needed and can give care to those who are in need.

Wiebe de Vries

Onderzoek \& Training

\section{References}

1. Bandura, A. (1995). Self-efficacy in changing societies. Cambridge university press.

2. De Vries, W. (2010). Remember fast. Act skillfully. Training methods for Basic Life Support; analysis from an educational perspective. VU Amsterdam.

3. Pellegrino, J.L., Oliver, E., Orkin A., Marentette, D., Snoblen, P., Muise, J., Joe Mulligan, J., De Buck E. (2017). A call for revolution in first aid education, refining the Utstein formula for survival. International Journal of First Aid Education, 1:1. 2017

4. Greif, R., Lockey, A.S., Conaghan, P., Lippert, A., De Vries, W., Soar, J., Monsieurs K.G. (2015). European Resuscitation Council Guidelines for Resuscitation 2015: Section 10. Education and implementation of resuscitation. Resusciation, 95, 288-301.

5. University of Leicester. (2013). Neuro-magic: Magician uses magic tricks to study the brain's powers of perception and memory. ScienceDaily. Retrieved April 30, 2017 from www.sciencedaily.com/releases/2013/03/130312092440.htm 